2 Foster, C. (2019) It is never lawful or ethical to withdraw life-sustaining treatment from patients with prolonged disorders of consciousness. Journal of Medical Ethics, 2019, 265-270.

3 Ruck Keene, A.C.E. \& Lee, A. (2019) Withdrawing life-sustaining treatment: a stock-take of the legal and ethical position. Journal of Medical Ethics, 45, 794-799.

4 Foster, C. (2019) Deal with the real, not the notional patient, and don't ignore important uncertainties. Journal of Medical Ethics, 45, 800-801.

5 Shweder, R.A. \& Bourne, E.J. (1982) Does the concept of the person vary cross-culturally? In Cultural Conceptions of Mental Health and Therapy (eds A.J. Marsella \& G.M. White), pp. 97-137. Springer.
6 Elixhauser, S. (2018) Negotiating Personal Autonomy Communication and Personhood in East Greenland. Routledge.

7 Hollan, D. (1992) Cross-cultural differences in the self. Journal of Anthropological Research, 48, 283-300.

8 Rasmussen, S. (2008) Personhood, self, difference, and dialogue (Commentary on Chaudhary). International Journal for Dialogical Science, 3, 31-54.

9 Alam, S. (2018) Perceptions of Self, Power, \& Gender Among Muslim Women: Narratives for a Rural Community in Bangladesh, pp. 73-105. Palgrave Macmillan.

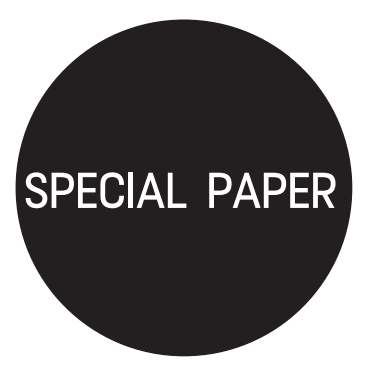

Independent Psychiatrist London, UK. Email: grands@ doctors.org.uk

${ }^{2}$ ST4 in Old Age Psychiatry, West of Scotland Higher Psychiatry Training Scheme, UK

${ }^{3}$ PhD, FRCS, FRCP, FRGS, Consultant Vascular and Renal Transplant Surgeon, Director of Research and Development University Hospitals Coventry and Warwick NHS Trust, UK

Conflicts of interest: None.

Keywords. Aetiology; dementia; organic syndromes; clinical neurology; cognitive neuroscience.

First received 11 Mar 2019 Final revision 19 Nov 2019 Accepted 2 Dec 2019

\section{doi:10.1192/bji.2020.1}

(c) The Authors 2020. This is an Open Access article, distributed under the terms of the Creative Comm Attribution licence Commons Attibution licence (http://creativecommons.org/ licenses/by/4.0/), which permits unrestricted re-use, distribution, and reproduction in any medium provided the original work is properly cited.

\title{
Post-flight confusion: does flying affect the brain?
}

\author{
Gianetta Rands, ${ }^{1} \odot$ Thomas McCabe ${ }^{2}$ and Chris Imray ${ }^{3}$
}

This paper describes a condition termed post-flight confusion using anecdotal and clinical observations. It reviews research from the fields of aviation and altitude medicine and how this could apply to some physiological changes that happen during commercial flights. The collection of symptoms observed is similar to those of delirium. More research is needed to validate these observations, to identify the risks of flying for older people and to consider not only how to minimise these risks but whether this situation contributes to our knowledge about the aetiologies of delirium and dementias.

Flying is now a common part of modern life. In 1998, it was estimated that 1 in 10 passengers who passed through UK major airports were over the age of 65 and mostly travelling for 'leisure' purposes. ${ }^{1}$ Recent data about the ages of air passengers are difficult to find and usually summarised in statements such as 'Senior travel is becoming a massive part of the travel industry'. Observations about post-flight confusional states have been made for over a decade ${ }^{3}$ and anecdotal adverse events are known to many clinicians working with older adults. These observations have been described in medical literature to the level of case reports. ${ }^{3,4}$ This paper describes some of these observations and considers likely aetiological factors.

\section{The passenger cabin environment}

Most of the research about the effects of higher altitudes on human physiology has been done on pilots and crew members in good physical health. There is no published research reflecting the challenges facing the older traveller with complex comorbidities. The cabin environment is artificially controlled, except for radiation, which is monitored. Planes cruise at altitudes of 30000 $40000 \mathrm{ft}$ (Table 1) and at this altitude air pressure is around $18.6 \mathrm{kPa}$, which is incompatible with life. Currently, cabin pressures are controlled at $74.5-84.1 \mathrm{kPa}$, corresponding to $6000-8000 \mathrm{ft}$ altitude (sea level is about $96.5 \mathrm{kPa}$ ). ${ }^{3}$ Some modern jets control their cabins to $6000 \mathrm{ft}$ and claim that fewer symptoms of 'jet lag' are experienced by their passengers.

Planes ascend to cruising heights in 20-30 min and descend at similar speed. Low air pressure is associated with expansion of air spaces (Boyle's law), which are present in bowels, sinuses and recent surgical sites. Lower air pressures are associated with peripheral oedema and potential bleeding from varices.

At sea level, peripheral oxygen saturation of the blood $\left(S_{\mathrm{pO} 2}\right)$ is normally $97-99 \%$, whereas at $6000-8000 \mathrm{ft}$ altitude there is a $20-26 \%$ reduction in available oxygen, which results in oxyhaemoglobin saturations of $83-85 \%$. Anecdotally, using a small pulse oximeter, $S_{\mathrm{pO} 2}$ values during a flight were entirely as predicted by physics, starting and ending at ground level at 98-99\%, with a range of 83-92\% from 20-30 min into the flight until descent at destination. A compensatory increase in pulse was sometimes noted. Although respiratory rates were not recorded, these increase as $S_{\mathrm{pO} 2}$ decreases.

Humidity at cruising cabin pressures can be as low as $1-20 \%$. Our 'comfort zone' is $50-65 \%$. Low humidity can result in dehydration and reduced peripheral perfusion.

There are no internationally agreed standards for cabin air quality. Cabin air may contain 
Table 1

Altitudes in feet and metres above sea level and known physiological changes in healthy human adults

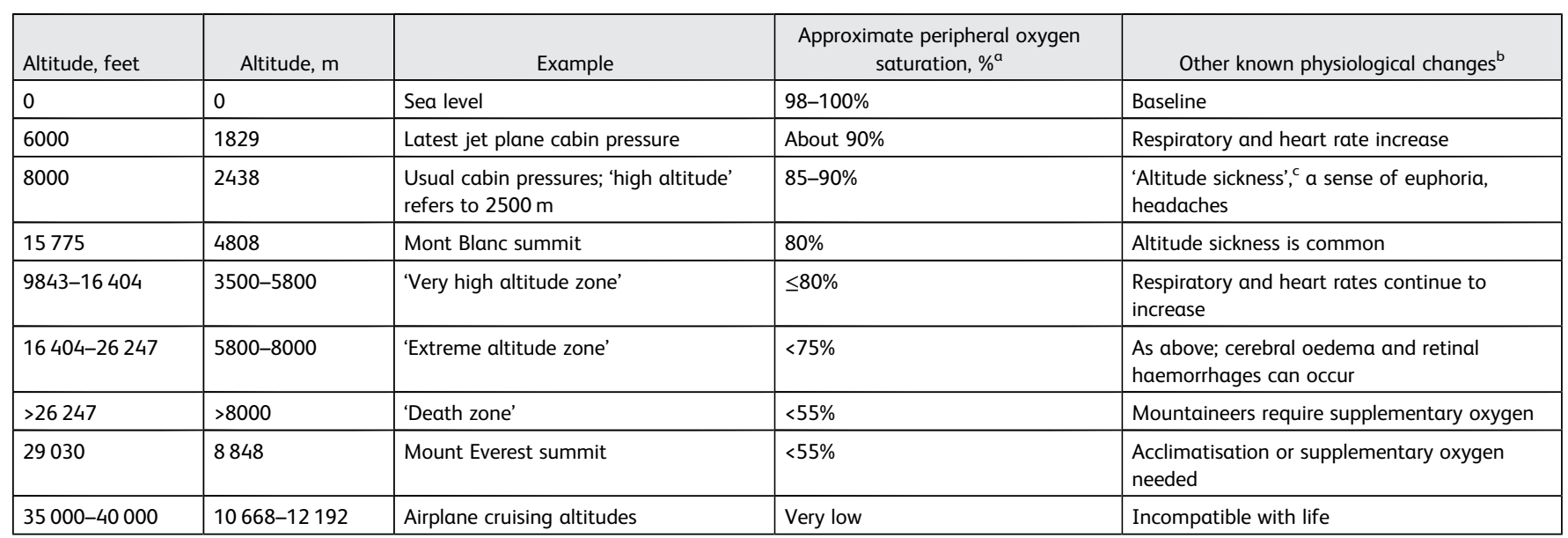

a.The rate of change in oxygen levels can affect physiological response.

b.There is individual variation in physiological response to increasing altitude and in how people feel with reduced oxygen levels.

c.Symptoms of altitude sickness include headache, nausea, vomiting, dizziness, fatigue and insomnia. Signs of altitude sickness include: raised pulse, respiratory rate, diastolic pressure and body temperature; peripheral and pulmonary oedema. ${ }^{5}$

elevated levels of carbon dioxide $\left(\mathrm{CO}_{2}\right)$, ozone and microbes that would be illegal in office spaces. ${ }^{3}$

\section{Basic physiology and brain responses to hypoxia and other aspects of in-flight environments}

Cerebral perfusion pressure is auto-regulated as the difference between blood pressure and intracranial pressure. Arterial carbon dioxide levels and local metabolic activity both increase cerebral perfusion. Low arterial oxygen rapidly results in increases in respiratory and heart rates and, over time, an increased haematocrit. As the skull has a fixed internal volume, it is the cerebrospinal fluid that buffers brain volume changes. Lower levels of inspired oxygen result in increases in intracranial pressure and can subsequently compromise perfusion of some brain regions.

Adenosine triphosphate (ATP) is the universal cellular energy currency, and as the levels of oxygen drop, a relative mismatch between the cellular ATP supply and demand can develop. This can result in cellular hypometabolism (Fig. 1). Depending on duration and the efficacy of the physiological response, this hypometabolism can result in cerebral cellular hypoxia and subsequent cell damage. Evidence indicates that physiological auto-regulation is impaired by increasing age,

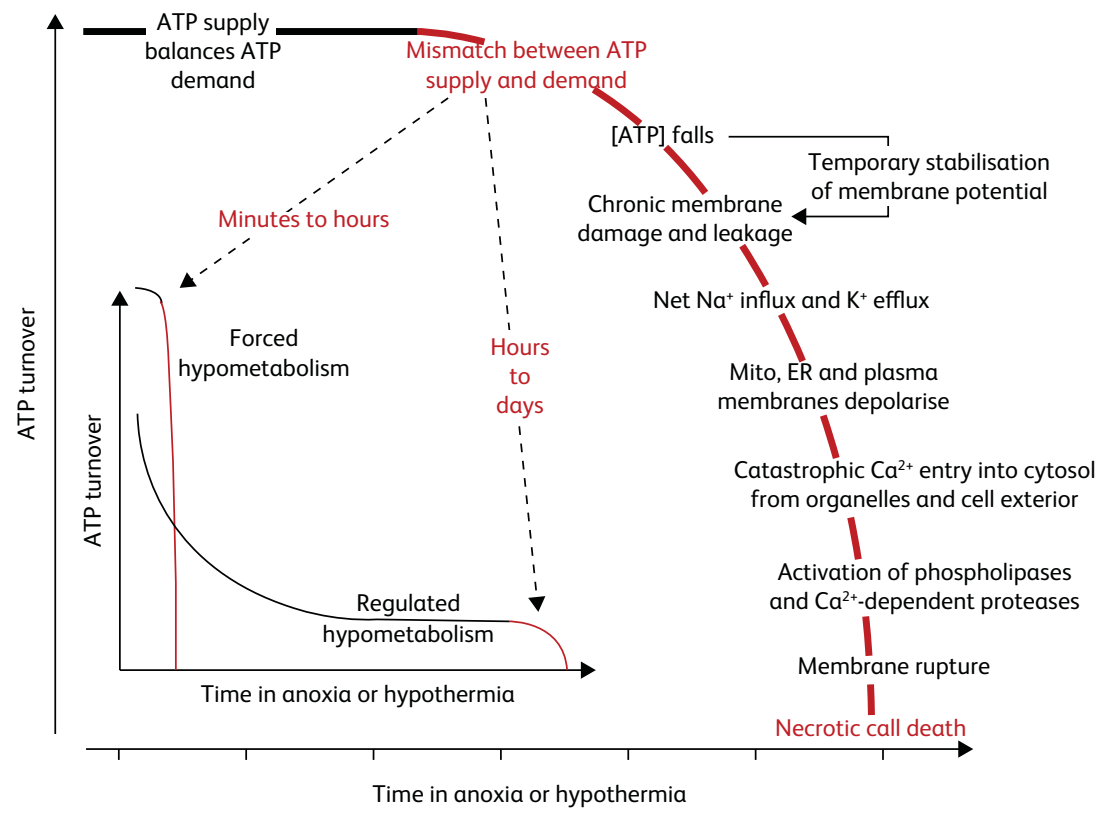

Fig. 1

Adenosine triphosphate (ATP) turnover of cells as a function of time exposed to anoxia and hypothermia (reproduced with permission ${ }^{6}$ ). Mito, mitochondria; ER, endoplasmic reticulum. 
sleep, alcohol and hypnotics, and there may be other factors, such as various medications.

There are a number of potential options that could reduce this effect, such as supplementary oxygen. Environmental modifications that might be beneficial may also have adverse effects. Modest increases in cabin pressure would improve cerebral oxygen delivery to all passengers but would have costly implications for airplane design.

\section{Cognitive effects of high altitude}

Interest in the cognitive effects of high altitude started with research by balloonists James Glaisher and Henry Coxwell in the 1860s, when both men became unconscious on rapid ascent to altitudes of approximately $25000 \mathrm{ft} .{ }^{7}$ In 1932, these effects were demonstrated with handwriting samples that became more jumbled with increasing altitude. A number of research studies have demonstrated specific cognitive difficulties at altitudes. For instance, in 2017 Griva et $a l^{8}$ assessed a range of cognitive functions after ascent to Everest base camp and found that attention, learning, verbal abilities and executive function declined to variable degrees with ascent to altitude. For trekkers, ascent to altitude was clearly slower and more effortful than for passengers in jet planes. There was a wide interindividual variability and the impairments were greater in older trekkers. It would appear that the older individual's cerebral circulation is more susceptible to relatively subtle changes in inspired oxygen levels.

\section{Discussion}

For many years, some airlines have been aware that their passengers may suffer respiratory problems after flying. They quote the figure as 1 in 4 passengers suffering this condition. ${ }^{9}$ They attribute this to the usual cabin pressures, which are equivalent to an altitude of $8000 \mathrm{ft}$. Aircrafts manufactured using the newest technology have a fuselage made of carbon fibre reinforced plastic, which does not suffer 'metal fatigue', and hence their cabin pressures can be greater. Metal fatigue occurs in aluminium and other metals because planes expand and contract during ascent and descent owing to increased differential pressures between cabin and surrounding air. The higher cabin pressures that can be achieved with this structure of fuselage (and newer versions in production) result in lower altitude equivalent pressures of approximately $6000 \mathrm{ft}$ and, it is claimed, only 1 in 12 passengers suffer subsequent respiratory distress from this acute, short-term altitude exposure.

More recently it has been suggested that jet lag could be similar to acute mountain sickness, which affects some individuals above $6500 \mathrm{ft}$ altitude. Focus remains on symptoms such as headache, nausea, lack of appetite, lack of energy and sleeplessness, with acknowledgement of the disruption of diurnal rhythms, ${ }^{10}$ rather than on any longer-term post-flight symptoms.

Post-flight confusion could be construed as a form of delirium. Acute confusional state or delirium is a common clinical syndrome characterised by disturbed consciousness, decline in cognitive function or changes in perception. It is estimated to occur in 10-20\% of medical patients admitted to hospital and is strongly associated with increased mortality, even after readjustment for severity of disease. ${ }^{11}$ Many causes of delirium are considered in a standard medical admission 'work-up'. However, sometimes underlying aetiology is not found, ${ }^{12}$ in which case we suggest that a history of recent flying should be considered.

In-flight medical emergencies are relatively rare, although they may be underreported because of commercial interests and maintaining customer confidence. Although the common cardiovascular, respiratory and surgical complications associated with pressure changes have been addressed in guidance and regulations produced by aviation authorities and commercial airlines, there is little about cognitive symptoms that may be caused or exacerbated by the described environmental changes. Indeed, mental health-related advice for flying in general is poorly approached by aviation authorities. 'Unpredictable, aggressive, dis-organised or disruptive' behaviour is cited in flying guidance from the Civil Aviation Authority, which is unhelpful to the casual reader when compared with guidelines on physical health. ${ }^{13}$

\section{Conclusions}

The laws of physics determine environmental changes at altitude. Research from the fields of aviation and altitude medicine informs us of human physiological changes in fit young men (as this research is rarely done on other individuals). Airlines are becoming aware that current cabin environments could be associated with symptoms similar to those found in altitude sickness. With few exceptions, such as deep vein thrombosis (DVT), there remains no systematic research into the health of passengers after they leave their destination airports.

Investigation is needed into the effects of flying environments and the manner in which human physiology adapts to high altitudes at different stages of our lifespan.

Post-flight confusion is anecdotally being seen more often and clinicians should identify people at risk and consider ways to minimise this risk. Research in this field may shed light on some mechanisms of delirium and contribute to our knowledge about aetiologies of dementia syndromes. This topic could have far-reaching effects for individuals flying and for the wider aviation business.

\section{Author contributions}

All three authors contributed to this paper and collaborated in making changes to it in response to the reviewers' comments. 


\section{References}

1 Parliamentary Office of Science and Technology (2000) Statistical Information on Air Passenger Numbers and Characteristics. www.parliament.uk (https://www.parliament.uk/ documents/post/e3.pdf).

2 Airport Guides Network (2020) Heathrow Airport Guide: Senior Travel. Airport Guides Network (https://www.heathrow-airportguide.co.uk/senior-travel.html).

3 Rands, G. (2002) Fear of flying, reviewed: an example of evidence-based old age psychiatry. Psychiatric Bulletin, 26, 188-90.

4 McCabe, T. (2017) 'Doc, can I fly to Australia?': a case report and review of delirium following long-haul flight. BJPsych Bulletin, 41, $30-2$

5 Johnson, C., Anderson, S., Dallimore, J., et al (2015) Oxford Handbook of Expedition and Wilderness Medicine (2nd edn). Oxford University Press.

6 Boutilier, R. G. (2001) Mechanisms of cell survival in hypoxia and hypothermia. Journal of Experimental Biology, 204, 3171-81.

7 West, J. B. (1998) High Life: A History of High-Altitude Physiology and Medicine. Oxford University Press.
8 Griva, K., Stygall, J., Wilson, M. H., et al (2017) Caudwell XTreme Everest: a prospective study of the effects of environmental hypoxia on cognitive functioning. PLOS ONE, 12(3): e0174277.

9 Baird F. (2015) Dreamliner cabin pressure tech reduces altitude sickness, benefits PaxEx. Apex (https://apex.aero/2015/12/10/ turning-down-the-cabin-pressure).

10 Zhang B. (2016) Boeing is making a major change to its planes that could end jet lag as we know it. Business Insider (https:/l www.businessinsider.com/boeing-787-dreamliner-777x-cabinpressure-jetlag-2016-9)

11 Tauro, R. (2014) Delirium awareness - improving recognition and management through education and use of a care pathway. BMJ Quality Improvement Reports, 2, u203195.w1451.

12 Wan, M. (2017) Delirium in older adults: diagnosis, prevention, and treatment. $B C M J, 59,165-70$.

13 Civil Aviation Authority (2020) Psychiatric conditions: information for health professionals on assessing fitness to fly. CAA (https://www.caa.co.uk/Passengers/Before-you-fly/Am-I-fitto-fly/Guidance-for-health-professionals/Psychiatric-conditions).

\title{
SPECIAL PAPER \\ Person-centred care and psychiatry: some key perspectives
}

\author{
Jed Boardman ${ }^{1} \odot$ and Subodh Dave ${ }^{2}$
}

${ }^{1}$ Senior Lecturer in Social Psychiatry, Institute of Psychiatry, Psychology and Neuroscience, London, UK.

Email: jedboard@atlas.co.uk

${ }^{2}$ Associate Dean, Royal College of Psychiatrists, London, UK

Keywords. Person-centred care; personal recovery; values-based; evidence-based.

First received 27 Aug 2019 Final revision 18 Mar 2020 Final revision 18 Mar 2020
Accepted 24 Mar 2020

\section{doi:10.1192/bji.2020.2}

(c) The Authors 2020. This is an Open Access article, distributed under the terms of the Creative under the

Attribution-NonCommercial-ShareAlike licence (http://creativecommons.org/licenses/by-nc-sa/ $4.0 /$ ), which permits noncommercial re-use, distribution, and reproduction in any mediur and reproducion in any medium, provided the same Creative Commons licence is included and the original work is properly cited. The written permission of Cambridge University Press must be obtained for commercial re-use.
This paper outlines the importance of person-centred approaches to the practice of contemporary medicine and psychiatry. In considering the many aspects of person-centred approaches it outlines some key perspectives, including freedom and human rights; improving individual practice and the quality of services; increasing clinicians' work satisfaction; combining value-based and evidence-based practice; and the training of future generations of psychiatrists.

Person-centred approaches have deep roots in medical practice and historically have been a part of both Eastern and Western approaches to medicine. ${ }^{1}$ They have been given a greater profile in the past 70 years and assume particular importance now with the move towards personalised medicine. Person-centred approaches are supported internationally by the World Health Organization, World Psychiatric Association and other professional and patient bodies. ${ }^{1,2}$

This paper, discussing the importance of person-centred approaches and highlighting some implications for psychiatric practice, is based on a recent report from the Royal College of Psychiatrists' Person-Centred Training and Curriculum Scoping Group, which we led. The recommendations of the report were focused on the training and work of core trainee psychiatrists in the UK. Although these recommendations may not be internationally applicable, we hope that a person-centred approach to practice will be.

\section{Why person-centred care?}

In many countries in the second half of the 20th century we saw a shift in the practice of medicine, not only in the technical delivery of care and treatment but also in the voice of the patient, moving from a predominantly acquiescent subject to a participatory agent. This has been accompanied by broader concerns that routine healthcare has become commodified and impersonal, with a focus on profits. Medical advances towards a more targeted 'precision-medicine' approach can only happen with a more personalised (and human) approach to care.

Internationally, these scientific advances and improvements in quality are inequitably distributed. The provision of healthcare varies dramatically, with over one billion people remaining without any access to healthcare. The rise in the prevalence of long-term and mental health conditions, accompanied by a significant strain on human and financial resources, has highlighted the need for integrated people-centred health services. $^{3}$ 